\title{
First and Second Waves of COVID-19 in Egypt: People's Adherence to Stay-at-Home Policy and its Impact on COVID-19 Spread
}

\author{
Sally A. Mehesin ${ }^{1}$, Sara S. Elgammal ${ }^{1}$, Shaimaa Sh. Soliman ${ }^{1}$ \\ ${ }^{1}$ Public Health and Community Medicine department
}

\begin{abstract}
:
Background: The acquisition of COVID-19 virus infection is known to be caused by droplet transmission. Social distancing is thought to be the major effective preventive measure. Objective: To compare community mobility and people's commitment to the stay-at-home policy and its impact on the incidence of COVID-19 virus infection during the first and second waves of the virus. Methods: This study utilized the official daily reports of the Egyptian Ministry of Health and Population (MOHP) about the numbers of new COVID-19 cases along with Google mapping of community mobility all over Egypt. These reports were analyzed to compare the number of weekly reported cases and people's mobility at different places between the first and second COVID-19 waves. Results: It was found that the Egyptian people less adhere to the stay-at-home policy in the second COVID-19 wave compared to the first one with more mobility to different places and the difference was statistically significant ( $0.018 \&<0.001$ ). There was more duplication of cases per week in the second wave compared to the first one and this difference was statistically significant $(\mathrm{p}$ 0.018). Conclusion: Egyptians were more committed to the stay-at-home policy with a less number of weekly reported cases of COVID-19 in the first wave in comparison to the second wave.
\end{abstract}

Keywords: Community mobility, Covid-19, Google mapping.

\section{Introduction:}

Social distancing can be applied as an effective measure to decrease the contact with other people. It is considered as a type of the non-pharmaceutical countermeasures (NPCs) aiming to reduce infection and alleviate the pressure on health systems. ${ }^{(1,2)}$ The World Health Organization (WHO) advised and urged all the governments around the world to apply social distancing in order to control the epidemic and deal with it as an emergency. ${ }^{(3)}$

Many of the affected countries in 2020 adopted the recommended lockdown policies and succeeded to downward slope of the epidemic curve and restrain the first wave of COVID-19. ${ }^{(4)}$ Unfortunately, most countries rushed out to mitigate the lockdown measures despite all the warnings about the consequences of early lockdown lifting. Thus, they were hit by a second COVID-19 wave. $^{(5)}$ For instance, many countries in Europe were affected by a second wave of COVID-19 since September 2020.

It was expected that these countries had learned the lesson from the first wave and would manage the second wave more appropriately. However, these countries had gone through a worse situation as they had more COVID-19 positive cases, ICU admissions, and deaths. The conclusion is

*Corresponding author: sally.hasan.12@ med.menofia.edu.eg

(c) (1) This article is an open access article distributed under the terms and conditions of the Creative Commons Attribution (CC BY) license (http://creativecommons.org/licenses/by/4.0/) 
Mehesin et al.; First and Second Waves of COVID-19: People's Adherence to Stay-at-Home and its Impact on COVID-19 Spread

that only a hard and strict lockdown measure would be effective in controlling the pandemic until the healthcare professionals around the world discover a cure for COVID-19. ${ }^{(6)}$

This study aimed to compare how much the Egyptian population committed to the stay-at-home policy enforced by the government between the first and second waves of COVID-19 pandemic and how this commitment affected the magnitude of COVID-19 epidemic in Egypt.

\section{Methods:}

Research design: This study correlated the lockdown measures and social distancing to the frequency of new COVID-19 cases in Egypt. We depended on Google mobility reports to assess the social mobility as well as the Egyptian Ministry of Health and Population (MOHP) daily reports as a source of information about the number of COVID-19 cases in Egypt.

\section{Time and setting of the study:}

In this study, we defined the first wave and analyzed its data in the period from 21 March 2020 shortly after the start of the official lockdown until 2 May 2020 which marks the end of Google mobility reports at this time.

The second wave was defined and analyzed in the period from 8 December 2020 until 19 January 2021 which marks the end of Google mobility reports and synchronizes with the second lockdown.

\section{Tools of the study:}

\section{1- Google mobility reports:}

They are open-source data, which charts movement trends over time by geography, across different categories of places such as retails and recreation, groceries and pharmacies, and residential agreement. Google released these reports on a weekly basis and made them accessible after agreeing to Google terms and conditions.

We used Google mobility data to map time and place changes in mobility across Egypt in 6 categories: residential areas, grocery \& pharmacies, workplaces, parks, retail and recreational areas, and transit stations. Each community mobility report dataset was presented by location and highlighted the percent change in visits to these places within a geographical area.

These reports showed how the visits and length of stay at different places changed in comparison to the baseline. They calculated these changes using the same kind of aggregated and anonymized data used to show popular times for places in Google Maps.

Changes for each day were compared to the baseline value for that day of the week: The baseline is the median value for the corresponding day of the week during the 
Mehesin et al.; First and Second Waves of COVID-19: People's Adherence to Stay-at-Home and its Impact on COVID-19 Spread

5-week period from Jan 3-Feb 6, 2020. The reports calculated these insights based on data from users who have opted-in to Location History for their Google Account. So, the data represented a sample of Google maps users. As with all samples, this may or may not represent the exact behavior of a wider population.

\section{2- The MOHP Daily Reports:}

Data about the numbers of new cases were obtained from the daily reports announced by the Egyptian MOHP which included also the numbers of COVID-19 related deaths, recoveries, and overall number of cases. These reports are announced on a daily basis on the official web page of the ministry.

Data management: Data were managed by an IBM compatible personal computer with SPSS statistical package version 23 (SPSS Inc. Released 2015. IBM SPSS statistics for windows, version 23.0, Armnok, NY: IBM Corp.). Data were expressed in: number (No), percentage $(\%)$, mean $(\bar{x})$, and standard deviation (SD). Paired t test was used to compare paired normally distributed data and Wilcoxon test was used to compare non-normally distributed data. Two-sided $\mathrm{P}$ - value of $<0.05$ was considered statistically significant.

Ethical consideration: This study was approved by the Institutional Review board of Faculty of Medicine, Menoufia University. Google reports were obtained after agreeing to Google terms and conditions. MOHP reports were freely available at the official web page of the ministry without any requirements.

\section{Results:}

During the first wave, marked reduction was found in the community mobility to retail and recreation by $66 \%$, followed by transit by $59.1 \%$, parks by $46.75 \%$, workplace by $40.8 \%$, and grocery \& pharmacies by $27.4 \%$. The mobility to residential places was increased by $17.1 \%$ (Table 1, Fig.1). Table (1) shows comparison between the first and second waves of COVID-19 in terms of reduction percentage in community mobility per week compared to baseline.

During the second wave, the reduction of community mobility to retail and creation was only by $21 \%$, followed by parks by $13.1 \%$, transit by $8.6 \%$, and workplace by $7 \%$. The increase of mobility to residential places was only $7.7 \%$. On the contrary to the first wave, there was increased mobility to grocery and pharmacies by $28.7 \%$ (Table 1, Fig. 2).

The reduction of mobility to retail and recreation was significantly higher during the first wave than the second one ( $p$ $<0.001)$. Moreover, the reduction in mobility to parks, transit, and workplace 
Mehesin et al.; First and Second Waves of COVID-19: People's Adherence to Stay-at-Home and its Impact on COVID-19 Spread

were significantly higher during the first wave than the second one $(\mathrm{P}<0.001$, $<0.001$, and $<0.001$, respectively). The reduction in mobility to grocery and pharmacies was reversed in the second wave where it showed a significant increase ( $\mathrm{p}<0.001)$, (Table 1).

The mean number of weekly reported cases infected with COVID-19 was $870.3 \pm 612.26$ in the first wave with a median of 869 . This number increased significantly to $6016.4 \pm 3343.12$ in the second wave with a median of 8136.00 (p $<0.001$ ) (Table 2, Fig. 3).

The mean number of deaths/weeks was $67.33 \pm 36.25$ (median= 69) in the first wave. This number increased significantly in comparison with the second wave to be $272.28 \pm 121.70($ median= 268$)$ with $\mathrm{p}$ value of 0.007 (Table 2). Table (2) shows comparison between first and second waves in terms of weekly recorded COVID-19 cases.

\section{Discussion:}

Despite the great efforts to control the initial spread of COVID-19 in Egypt, there was an acceleration in the daily-confirmed cases, reaching a peak of 1,774 in the first wave and another peak of over 1,400 per day in the second wave before subsequently falling off to around 700 per day in late January 2021.
All the governments conducted social distancing measures and even lockdown policies to stop COVID-19 virus dissemination. Schools were closed, mass gatherings were prevented, and there was cessation of air traffic movement.

These measures were implemented gradually in many ways and with varying degrees in the different countries. In this study, we utilized Google community mobility reports (CMR) and daily reports announced by the Egyptian Ministry of Health.

Social distancing has many tradeoffs. It is not possible to maintain this distancing from the financial and economic point of view. These lockdown measures led to many socioeconomic hardships and caused catastrophic shocks to the global financial markets. ${ }^{(7)}$

COVID-19 has caused unprecedented unemployment benefits claims within the US, reaching up to 17 million in mid-April 2020. ${ }^{(8)}$ With the loss of jobs, there were disruptions in supply chains, especially in the food industry. ${ }^{(9,10)}$ Food shortages affected countries, especially those who rely on imports from other countries. ${ }^{(11)}$

This study compared the difference between commitment of people to the spacing measures recommended by health authorities during the first and second 
Mehesin et al.; First and Second Waves of COVID-19: People's Adherence to Stay-at-Home and its Impact on COVID-19 Spread

waves and its impact on the rate of weekly increase of COVID-19 cases. Less reduction was noticed in the percentage of community mobility to the following places (retail, parks, transit stations, and work) in the second wave compared to the first one. Going to grocery and pharmacies increased more than the baseline in the second wave while in the first wave, it was decreased.

There was lesser increase in the duration of stay at home during the second wave compared to baseline than that in the first wave.

A prediction model was created by University of Washington Health Index and Evaluation Center (IHME). ${ }^{(12)}$ The model analyzed the epidemic situation in 7 locked down cities which implemented and maintained social lockdown. They cities include Wuhan, Italy, and Spain. The epidemic quickly reached a peak in these cities and so far not climbing again.

Qian and Jiang (13) reviewed the literature and found that after applying social distancing measures, 309 cities reported zero cases and 34 cities had confirmed cases in China as of April 13, 2020.

Khatee et al., ${ }^{(14)}$ studied the effects of social distancing on the spread of COVID19 based on cell phone data and concluded that social distancing not only reduces the basic reproduction number of infections, but also shortens the time for epidemic peak. However, this latter effect is unexpected as the changes in behavior should reduce transmission immediately which did not happen in some countries such as Belgium. They attributed this unexpectedness to other unclear means.

The application of isolation and quarantine for SARS epidemic was much more successful because most of SARS cases were symptomatic and identifiable, thus could be easily isolated. SARS viral load peaked at 12-14 days from the onset of illness where, by this time, the patient would be already in the hospital. One more important point is that the low or absent viral shedding from the upper respiratory tract early in the disease made early isolation more effective. ${ }^{(15)}$

This study highlighted the relaxing attitude of people in the second wave as their mobility to different places like parks, grocery, retail and recreational areas was increased in the second wave compared to the first wave with statistically significant difference. Consequently, there were more average weekly recorded cases of COVID19 in the second wave compared to the first wave.

The restrictive measures and voluntary social distancing adopted by the Eurozone 
Mehesin et al.; First and Second Waves of COVID-19: People's Adherence to Stay-at-Home and its Impact on COVID-19 Spread

resulted in significant drop in people's mobility during the first wave of COVID 19 (March and April 2020). However, people were more active during the second wave of COVID-19 despite the application of the same restrictive measures. ${ }^{(16)}$

The same result was observed by da Silva et al. ${ }^{(17)}$ who compared the first and second COVID-19 waves through performing a multi-objective time series analysis of community mobility reduction. The researchers observed that mobility reduction was stronger in the first wave compared to the second one; December holidays and shopping seasons had increased mobility in all the studied categories, but contrasting results were recorded for parks (with more mobility reduction) and grocery $\&$ pharmacies (with increased mobility).

These observations included 5 highly impacted cities by the COVID-19 epidemic: Lombardia, ^Ile-de-France, Birmingham, Berlin, and Toronto.

\section{Limitations of the study:}

Some data were not announced by the Ministry of Health in Egypt such as the number of daily-screened people that would have helped us to calculate the disease incidence. Also, there was no definite official time for the beginning or the end of the epidemic waves. So, we defined it depending on the time of the regulated lockdown and the time interval of the nearest launched Google report.

\section{Conclusion:}

Egyptian people had responded more strongly to the stay-at-home policy during the first wave compared to the second wave; there was more reduction in mobility to different places like work, transit stations, recreational areas, parks, and longer duration of staying at home.

Mobility to grocery \& pharmacies was not only less reduced than the first wave, but it was also increased over the usual baseline. This pattern of difference between the two waves resulted in more increase and even duplication of COVID-19 cases during the second wave compared to the first wave.

Competing interests: No competing interests.

Fund: No fund was received for this work.

Acknowledgment: No acknowledgment

\section{References:}

1. Anderson RM, Heesterbeek $\mathrm{H}$, Klinkenberg D, et al. How will countrybased mitigation measures influence the course of the COVID-19 epidemic? Lancet. 2020 Mar 21; 395(10228): 931934.

2. European Centre for Disease Prevention and Control. Guidelines for the use of 
Mehesin et al.; First and Second Waves of COVID-19: People's Adherence to Stay-at-Home and its Impact on COVID-19 Spread

non-pharmaceutical measures to delay and mitigate the impact of 2019-nCoV Stockholm. ECDC; 2020.

3. United Nations. COVID-19: 'Top priority' must be on containment, insists WHO's Tedros: UN News; 2020. Available at: https://news.un.org/en/story/2020/03/10 58461. Last accessed 15 April, 2021.

4. World Health Organization, "Advice for the public". Available at: https://who.int/emergencies/diseases/no vel-coronavirus-2019/advice-for-public 2020. Last accessed 20 April 2021.

5. Xu S, Li Y. Beware of the second wave of COVID-19. Lancet. 2020 Apr 25;395(10233):1321-1322.

6. Graichen H. What is the difference between the first and the second/third wave of Covid-19? - German perspective. J Orthop. 2021 MarApr;24:A1-A3.

7. Saintvilus R. Coronavirus Market Volatility: Have We Reached The Bottom? Nasdaq. 2020. available at Coronavirus Market Volatility: Have We Reached The Bottom? | Nasdaq . Last accessed 18 May 2021.

8. Cohen P, Hsu T. Sudden Black Hole for the Economy With Millions More Unemployed. The New York Times 2020. available at: 'Sudden black hole' for the economy with millions more unemployed - Charlotte Business Journal (bizjournals.com). Last accessed 18 May 2021.

9. Corkery M, Yaffe-Bellany D. Food Supply Chain Is Strained as Virus Spreads. The New York Times 2020. available at : U.S. Food Supply Chain Is Strained as Virus Spreads - The New York Times (nytimes.com). Last accessed 18 May 2021.

10. Harvey F. Coronavirus measures could cause global food shortage, UN warns. The Guardian 2020. available at : Coronavirus measures could cause global food shortage, UN warns | Food security | The Guardian. Last accessed 20 May 2021.

11. Shah J, Karimzadeh S, Al-Ahdal T et al. COVID-19: the current situation in Afghanistan. Lancet Glob Health. 2020 Jun; 8(6):e771-e772.

12. IHME COVID-19 health service utilization forecasting team, Murray C. Forecasting COVID-19 impact on hospital bed-days, ICU-days, ventilatordays and deaths by US state in the next 4 months. Preprint. medRxiv. 2020.03.27.20043752.

13. Qian M, Jiang J. COVID-19 and social distancing. Z Gesundh Wiss. 2020 May $25: 1-3$ 
Mehesin et al.; First and Second Waves of COVID-19: People's Adherence to Stay-at-Home and its Impact on COVID-19 Spread

14. Khataee H, Scheuring I, Czirok A et al. Effects of social distancing on the spreading of COVID-19 inferred from mobile phone data. Sci Rep. 2021 Jan $18 ; 11(1): 1661$.

15. Wilder-Smith, A, Freedman, DO. Isolation, quarantine, social distancing and community containment: pivotal role for old-style public health measures in the novel coronavirus (2019-nCoV) outbreak, Journal of Travel Medicine, Volume 27, Issue 2, March 2020, taaa020, https://doi.org/10.1093/jtm/taa a020
16. Colijin B, Konings J, Spakman T. Voluntary social distancing weaker in second wave. Released Feb. 2021. Available

at: https://think.ing.com/articles/eurozonevoluntary-social-distancing-weaker-insecond-wave/. Accessed April $10^{\text {th }}$ 2021.

17. Da Silva G, De Almeida F, Oliveira S et al. Multi-objective time series analysis of community mobility reduction comparing first and second COVID-19 waves. arXiv preprint arXiv:2103.00535. 2021 Feb 28.

Table (1): Comparison between the first and second waves of COVID-19 in terms of reduction percentage in community mobility per week compared to base line

\begin{tabular}{|c|c|c|c|c|}
\hline Variables & First wave & Second wave & Wilcoxon test & P value \\
\hline $\begin{array}{c}\text { - Retail and recreation } \\
\text { Mean } \pm \text { SD }\end{array}$ & $-66.0 \pm 13.6$ & $-21.0 \pm 3.9$ & 2.37 & $0.018^{*}$ \\
\hline $\begin{array}{c}\text { - Parks } \\
\text { Mean } \pm \text { SD }\end{array}$ & $-46.7 \pm 8.8$ & $-13.1 \pm 5.2$ & 2.38 & $0.018^{*}$ \\
\hline $\begin{array}{c}\text { - Transit } \\
\text { Mean } \pm S D\end{array}$ & $-59.1 \pm 11.1$ & $-8.6 \pm 8.9$ & 2.37 & $0.018^{*}$ \\
\hline $\begin{array}{c}\text { - Work places } \\
\text { Mean } \pm S D\end{array}$ & $-40.8 \pm 12.3$ & $-7.0 \pm 7.4$ & 2.37 & $0.018^{*}$ \\
\hline $\begin{array}{c}\text { - Grocery and } \\
\text { pharmacies } \\
\text { Mean } \pm S D\end{array}$ & $-27.4 \pm 10.3$ & $28.7 \pm 6.5$ & 2.37 & $0.018^{*}$ \\
\hline $\begin{array}{c}\text { - Residential places } \\
\text { Mean } \pm S D\end{array}$ & $17.1 \pm 1.3$ & $7.7 \pm 1.6$ & 2.39 & $0.017^{*}$ \\
\hline
\end{tabular}

* Significant. 
Mehesin et al.; First and Second Waves of COVID-19: People's Adherence to Stay-at-Home and its Impact on COVID-19 Spread

Table (2): Comparison between first and second waves in terms of weekly recorded COVID-19 cases

\begin{tabular}{|l|c|c|c|c|}
\hline \multicolumn{1}{|c|}{ Variables } & First wave & Second wave & Wilcoxon test & P value \\
\hline $\begin{array}{l}\text { - Recorded COVID-19 } \\
\text { cases/ week }\end{array}$ & & & & \\
Mean \pm SD & $870.3 \pm 612.26$ & $6016.4 \pm 3343.12$ & 2.37 & $0.00^{*}$ \\
Median & 869.00 & 8136.00 & & \\
IQR & 1036 & 5136.00 & & \\
\hline - Deaths/week & & & & \\
Mean \pm SD & $67.33 \pm 36.25$ & $272.28 \pm 121.70$ & 2.71 & $0.007^{*}$ \\
Median & 69.0 & 268.0 & & \\
IQR & $30.0-97.0$ & $164.0-388.0$ & & \\
\hline
\end{tabular}

* Significant.

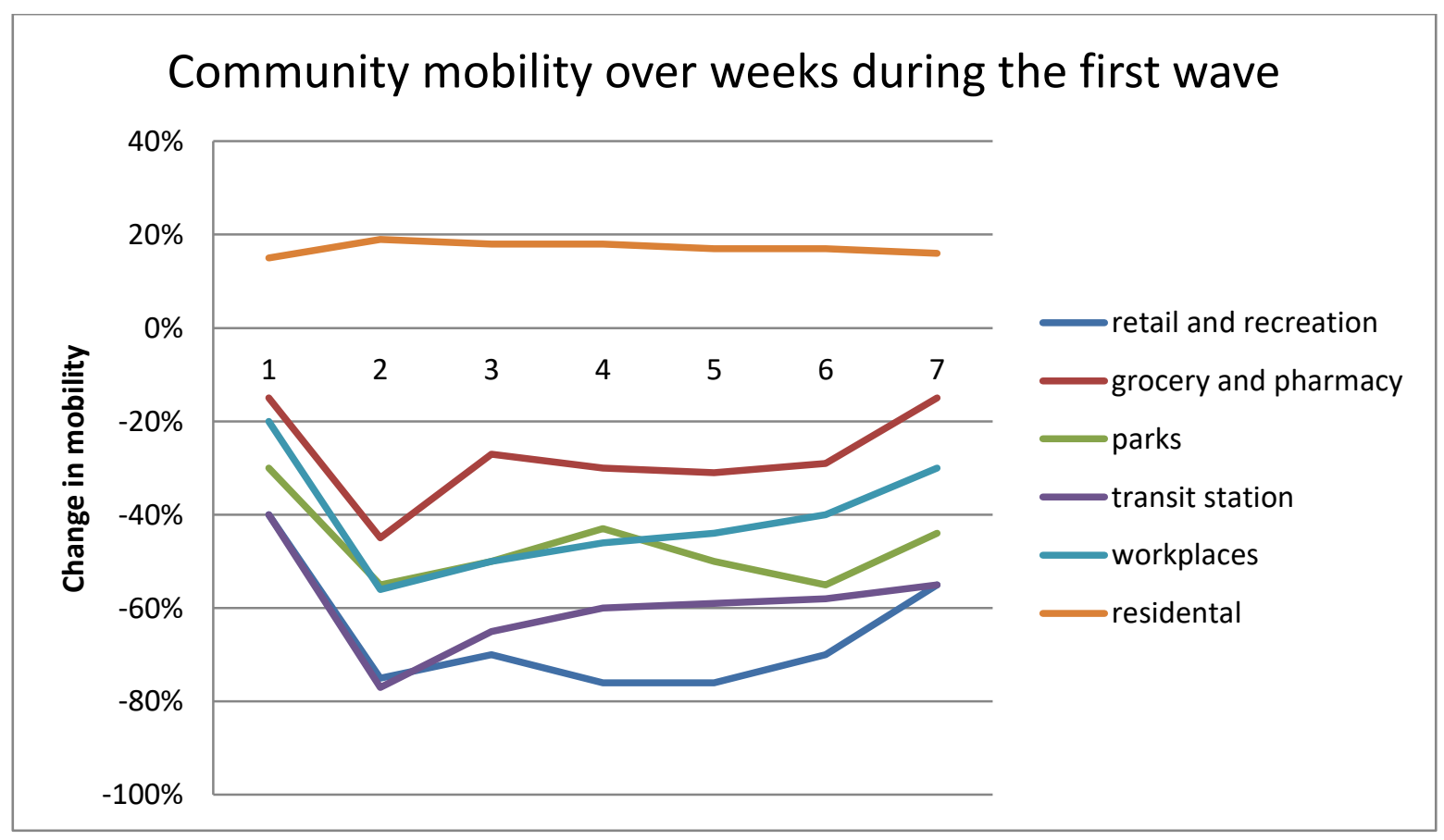

Figure (1): Change in community mobility (in weeks) during the first wave 
Mehesin et al.; First and Second Waves of COVID-19: People's Adherence to Stay-at-Home and its Impact on COVID-19 Spread



Figure (2): Change in community mobility (in weeks) during the second wave

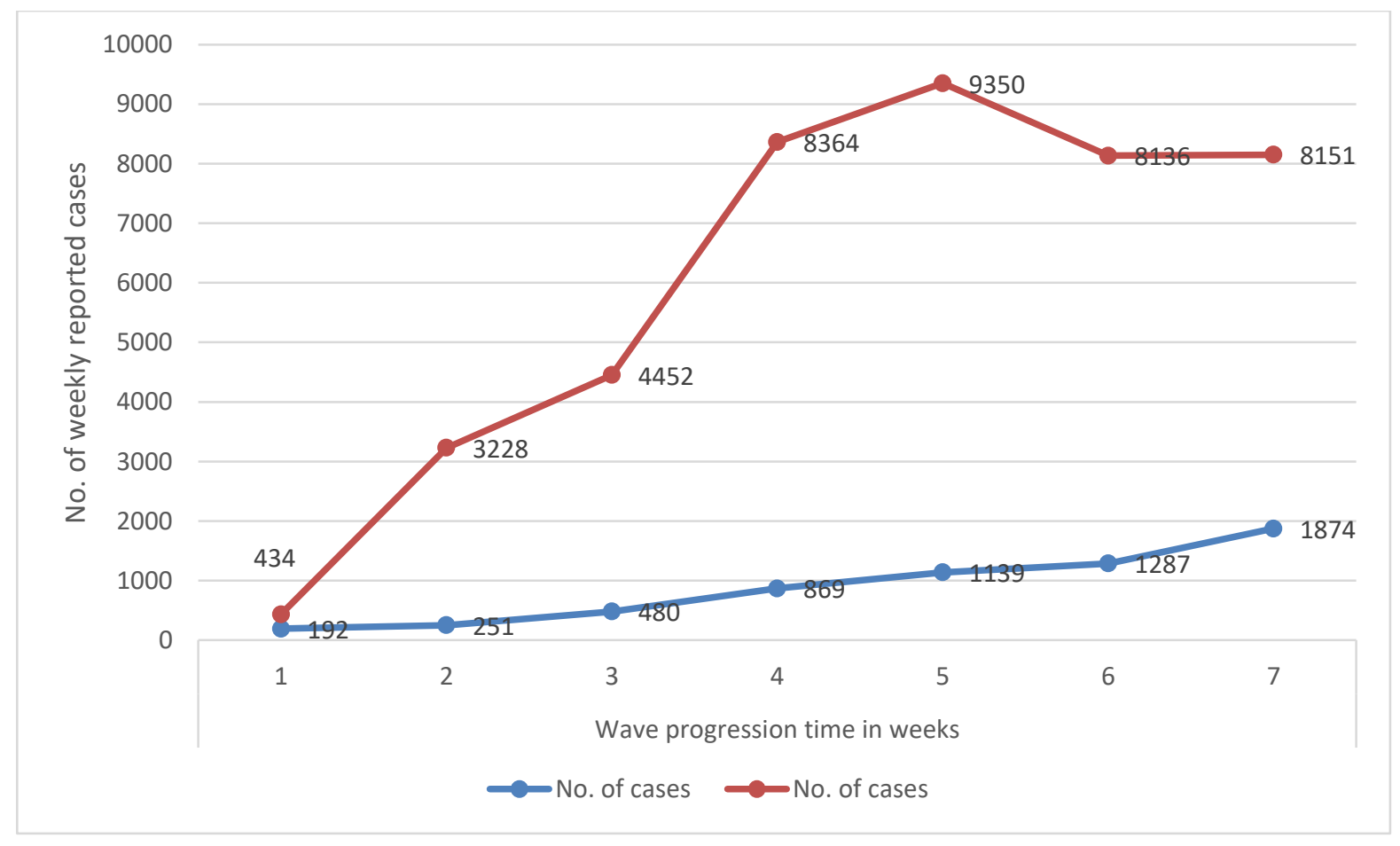

Figure (3): Weekly recorded cases of COVID-19 during the first and second waves 
Mehesin et al.; First and Second Waves of COVID-19: People's Adherence to Stay-at-Home and its Impact on COVID-19 Spread



